\title{
The effect of internet addiction and smartphone addiction on sleep quality among Turkish adolescents
}

\author{
Ayla Acikgoz ${ }^{\text {Corresp., } 1}$, Burcu Acikgoz ${ }^{2}$, Osman Acikgoz $^{3}$ \\ ${ }^{1}$ Vocational School of Health Services, Dokuz Eylül University, Izmir, Izmir, Turkey \\ 2 Department of Physiology, Graduate School of Health Sciences, Dokuz Eylül University, Izmir, Izmir, Turkey \\ 3 Department of Physiology, Faculty of Medicine, Dokuz Eylül University, Izmir, Izmir, Turkey \\ Corresponding Author: Ayla Acikgoz \\ Email address: ayla.acikgoz@deu.edu.tr
}

Background: Sleep quality plays a principal role in the protection of health. There is an increasing number of studies in the literature demonstrating that internet addiction and smartphone addiction impair sleep quality. However, the number of studies on Turkish adolescents is very limited. Therefore, this study examined the effects of internet addiction and smartphone addiction on sleep quality among Turkish adolescents. Methods: Participants in this cross-sectional study were 910 adolescents aged 13-18 years. Data were collected with the Short Internet Addiction Test, Smartphone Addiction Scale, and Pittsburgh Sleep Quality Index. In addition, a questionnaire was used to gather information about the demographic, socioeconomic, and health-related characteristics. Pearson's chisquare test, chi-square test for trend, Mann-Whitney $U$ test, logistic regression analysis, and Spearman's correlation analysis were used in the analysis. Results: The sleep quality of $58.7 \%$ of the adolescents was poor. Additionally, girls and adolescents $\geq 16$ years old had poor sleep quality. Sleep quality deteriorated as perceived health status and perceived economic status of family deteriorated. Compared to participants with normal internet addiction scores, poor sleep quality was 1.83 (95\% Cl: 1.22-2.74) times higher in those with problematic internet addiction and 1.99 (95\% Cl: 1.23-3.87) times higher in those with pathological internet addiction. One point increase in Smartphone Addiction Scale total score increased poor sleep quality 1.01 (95\% Cl: 1.00-1.02) times. Sleep quality scale were positively correlated with the smartphone addiction and internet addiction. However, there was no positive correlation between habitual sleep efficiency subcomponent of sleep quality and smartphone addiction and internet addiction.

Conclusions : Internet addiction and smartphone addiction were associated with poor sleep quality in adolescents. Older adolescents ( $\geq 16$ years), gender (female), poor health perception, and perception of moderate economic status of the family were other factors associated with poor sleep quality.

Peer) reviewing PDF | (2021:08:64535:3:0:NEW 11 Jan 2022) 


\section{The effect of internet addiction and smartphone addiction 2 on sleep quality among Turkish adolescents}

3

4
Ayla Acikgoz ${ }^{1}$, Burcu Acikgoz ${ }^{2}$, Osman Acikgoz ${ }^{3}$

.

${ }^{1}$ Vocational School of Health Services, Dokuz Eylul University, Izmir, Turkey.

${ }^{2}$ Department of Physiology, Graduate School of Health Sciences, Dokuz Eylul University, Izmir, Turkey.

${ }^{3}$ Department of Physiology, Faculty of Medicine, Dokuz Eylul University, Izmir, Turkey.

2

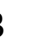

Corresponding Author:

Ayla Acikgoz

Vocational School of Health Services, Dokuz Eylul University

Balcova, Izmir 35340, Turkey

E-mail address: ayla.acikgoz@deu.edu.tr 
Abstract

34

Background: Sleep quality plays a principal role in the protection of health. There is an increasing number of studies in the literature demonstrating that internet addiction and smartphone addiction impair sleep quality. However, the number of studies on Turkish adolescents is very limited. Therefore, this study examined the effects of internet addiction and smartphone addiction on sleep quality among Turkish adolescents.

Methods: Participants in this cross-sectional study were 910 adolescents aged 13-18 years. Data were collected with the Short Internet Addiction Test, Smartphone Addiction Scale, and Pittsburgh Sleep Quality Index. In addition, a questionnaire was used to gather information about the demographic, socioeconomic, and health-related characteristics. Pearson's chi-square test, chi-square test for trend, Mann-Whitney U test, logistic regression analysis, and Spearman's correlation analysis were used in the analysis.

Results: The sleep quality of $58.7 \%$ of the adolescents was poor. Additionally, girls and adolescents $\geq 16$ years old had poor sleep quality. Sleep quality deteriorated as perceived health status and perceived economic status of family deteriorated. Compared to participants with normal internet addiction scores, poor sleep quality was 1.83 (95\% CI: 1.22-2.74) times higher in those with problematic internet addiction and 1.99 (95\% CI: 1.23-3.87) times higher in those with pathological internet addiction. One point increase in Smartphone Addiction Scale total score increased poor sleep quality 1.01 (95\% CI: 1.00-1.02) times. Sleep quality scale were positively correlated with the smartphone addiction and internet addiction. However, there was no positive correlation between habitual sleep efficiency subcomponent of sleep quality and smartphone addiction and internet addiction.

Conclusions: Internet addiction and smartphone addiction were associated with poor sleep quality in adolescents. Older adolescents ( $\geq 16$ years), gender (female), poor health perception, and perception of moderate economic status of the family were other factors associated with poor sleep quality.

60

Keywords: Sleep quality, internet addiction, smartphone addiction, adolescents. 


\section{Introduction}

67

Internet, a new communication, education, and entertainment medium, has become an indispensable part of our daily life of its users recently. The proportion of young people aged between 15 and 24 years old using the internet has reached $98 \%$ in developed countries and $66 \%$ in developing countries (International Telecommunication Union Development Sector, 2021). Excessive internet use has been described in different terms, including internet addiction (IA), pathological internet use, internet use disorder, and problematic internet use. IA is the most used term describing excessive internet use (Shaw \& Black, 2008). IA, which is defined as the inability of a person to control internet use, may impair an individual's psychological state and lead to problems in daily life (Pawlikowski, Altstötter-Gleich \& Brand, 2013). IA can have adverse effects on many lifestyle-related factors in adolescents, including time management, irregular eating habits, physical dysfunction, shortened sleep duration, and poor sleep quality (SQ). Moreover, IA is associated with negative health outcomes such as anxiety disorder, stress, depression, attention deficit/hyperactivity disorder, self-identity confusion, low self-esteem, social anxiety, and suicide attempt (Choi et al., 2015; Koças \& Şaşmaz, 2018; Onat et al., 2019; Salama, 2020; Lachmann et al., 2017).

Smartphones are devices that provide access to the internet in any environment. The use of smartphones has been increasing. While 6.4 billion people are reported to be using smartphones in 2021, this number is expected to reach 7.5 billion in 2026 (Statista, 2021). Although smartphones have made our lives more convenient due to their numerous benefits such as providing faster and easier communication, being a means for socialization and entertainment, facilitating access to information, and improving time management, excessive use may result in smartphone addiction (SA) (Kwon et al., 2013; Panova \& Carbonell, 2018). There are no official diagnostic criteria for SA. Based on the definition of IA, SA can be defined as the excessive use of smartphones that disrupts the daily life of its users (Demirci, Akgönül \& Akpinar, 2015). The components of SA are compulsive behavior, tolerance, withdrawal, and functional impairment 
92 (Kwon et al., 2013; Panova \& Carbonell, 2018). SA is stated to directly cause a variety of health symptoms. Since SA leads to a sedentary lifestyle in adolescents, it increases the incidence of physical symptoms such as lack of physical energy, physiological dysfunction and weakened immunity (Wang et al., 2021; Xie, Dong \& Wang, 2018). Although it has not been clearly defined yet, SA mostly occurs with symptoms such as not being able to stay away from the phone, checking the phone frequently, insomnia due to excessive smartphone use, and deterioration of SQ (Wang et al., 2021; Kocamaz et al., 2020; Kurugodiyavar et al., 2018).

Sleep is one of the basic life activities that affect the quality of life and health of individuals and is a concept with physiological, psychological and social dimensions. Good sleep is essential for survival (Brown et al., 2018). It plays a principal role in the protection of health and the functioning of central nervous, immune, hormonal, and cardiovascular systems (Brown et al., 2018; Kazama, Maruyama \& Nakamura, 2015; Nam, Han \& Lee, 2017; Medic et al., 2017, Tarokh et al., 2016). SQ consists of five dimensions: sleep duration, sleep continuity or efficiency, timing, alertness/sleepiness, and satisfaction/quality (Buysse et al., 1989). Adequate sleep and good SQ are vital in strengthening physical growth and academic performance in adolescents (Bilgrami et al., 2017; Lemma et al., 2014). Poor SQ is associated with depressive symptoms, poor connection with the school, impaired daytime functioning, weaker immune system, and fatigue (Bilgrami et al., 2017; Brown et al., 2018). In the literature, it is stated that age, gender, psychosocial, socioeconomic and cultural factors play a role on SQ as well as daily living habits that are at the level of addiction (Huang et al., 2020; Knutson, 2013; Kurugodiyavar et al., 2018; Wang et al., 2019; Özcan, 2020). These factors can be confounding factors when examining the effect of IA and SA on SQ. In the literature, studies conducted with adolescents indicate that the frequency of poor SQ increases with age (Demirci et al., 2015; Wang et al., 2019). It is stated that sleep deprivation increases the daytime sleepiness and careless behaviors of adolescents and affects their behavioral problems. Poor SQ is an important problem that needs to be treated during adolescence with emotional, cognitive or behavioral problems. (Demirci, Akgönül \& Akpinar, 2015; Tarokh et al. 2016).

Adolescence is defined by World Health Organization as the life stage between childhood and adulthood, between the ages of 10 and 19. Adolescence are grouped into three overlapping age groups: early adolescence (the age group between 10 and 15 years), middle adolescence (the age group between 14 and 17 years), late adolescence (the age group between 16 and 19 years). 
123 Because the changes seen in adolescents are not constant and occur at different ages for different 124 adolescents, there is overlap in age groups. (World Health Organization, 2010). Adolescence is a 125 critical period when a person is prone to addiction (Brown et al., 2018). Internet use and 126 smartphones have become common among adolescents and young adults (Kurugodiyavar et al., 127 2018; Lachmann et al., 2017; Lee, Kim \& Choi, 2017). According to the data of 2021 in Turkey, $12896.7 \%$ of people in the 16-24 age group use smartphones and 95.7\% use the internet (Turkish 129 Statistical Institute, 2021). Considering that the internet and/or smartphones are used extensively 130 by adolescents (Bilgrami et al., 2017; Choi et al., 2015; Lee, Kim \& Choi, 2017), their effects on 131 sleep disorders, which are associated with many health problems, should be examined closely. 132 Many studies have shown an association between excessive internet and/or smartphone use and 133 bedtime procrastination, shorter sleep duration, and sleep disturbances in adolescents (Bruni et 134 al., 2015; de Lima \& Silva, 2018; Huang et al., 2020; Kang et al., 2020; Lin et al., 2019; Wang 135 et al., 2021; Xie, Dong \& Wang, 2018). Moreover, poor SQ in adolescence negatively affects 136 learning, memory, attention, and cognition, therefore reduces academic success (Brown et al., 137 2018; Tarokh et al. 2016). Studies in Turkey investigating the effects of IA and/or SA on sleep 138 quality have mostly been conducted on adults or university students (Demirci et al., 2015; 139 Demirci, Akgönül \& Akpinar, 2015; Kocamaz et al., 2020; Özcan, 2020). However, there are 140 few studies conducted on adolescents (Akçay \& Akçay, 2018; Ekinci et al., 2014; Eliacik et al., 141 2016; Koças \& Şaşmaz, 2018; Onat et al., 2019). There are some limitations in most of these 142 studies examining the relationship between IA and SA, which are important addictions for 143 adolescents of the last quarter century, and sleep quality. Two of these studies were conducted on 144 the patient group (Eliacik et al., 2016; Onat et al., 2019). In another study, SQ was determined with a semi-structured scale whose validity and reliability were not determined (Ekinci et al., 146 2014). In one of the two studies conducted with healthy adolescents, the sample size was 147 relatively small and IA and SA were not determined by scales, and the correlation between 148 media (smartphone, computer, television) use and sleep quality was examined (Akçay \& Akçay, 149 2018). In a study with a sufficient sample size and in which IA and SQ were determined with 150 appropriate scales, the most important factor causing poor SQ was found to be IA (Koças \&

151 Şaşmaz, 2018). There is no study in the literature examining the effect of SA on SQ in 152 adolescents in Turkey. Therefore, new studies examining the effects of IA and SA on SQ are 153 needed to compensate for this gap in the literature. Internet usage in the adolescent age group is 
154 very high in Turkey (International Telecommunication Union Development Sector, 2021). It is

155 stated that IA and SA addiction and the risk of addiction are high in this age group (Eliacik et al., 156 2016; Koças \& Şaşmaz, 2018; Onat et al., 2019). It is important to relate these addictions to 157 potential health consequences that may affect adolescent health. Studies are needed to determine 158 the possible effect on sleep quality in order to detect and prevent IA and SA status among high 159 school students and to make treatment interventions.

Within this scope, this study aimed to investigate the effect of IA and SA on SQ in

161

162

163

164

165

166

167

168

169

170

171

172

173

174

175

176

177

178

179

180

181

182 183

Turkish adolescents and to identify the sociodemographic factors affecting SQ.

Based on the aforementioned information, the following hypotheses have been developed.

Hypothesis 1: IA negatively affects SQ in adolescents.

Hypothesis 2: SA negatively affects SQ in adolescents.

Hypothesis 3: Adolescents' sociodemographic (age, gender, body mass index, health status) and familial characteristics (parental education and family economic status) negatively affect SQ.

\section{Material \& Methods}

This cross-sectional study was conducted with Turkish adolescents aged 13-18 years in Izmir Turkey between March-April 2018. Participants consisted of students studying at a public high school $(\mathrm{N}=593)$ and two private high schools $(\mathrm{N}=659)$. Students at the public high school were from different parts of the city as they were enrolled in the school according to the results of a central exam. The students of the two private schools were also from different parts of the city and some were staying in the dormitory of the school. Therefore, the participants had different socio-cultural backgrounds, which may partially reflect the general society. All students were invited to complete the questionnaires of the study, with no sampling. 910 of the 1252 students completed the questionnaires and the response rate was $72.7 \%$.

All participants were assessed using three standardized questionnaires: The Short Internet Addiction Test (s-IAT) (Pawlikowski, Altstötter-Gleich \& Brand, 2013), Smartphone Addiction Scale (SAS) (Kwon et al., 2013), and Pittsburgh Sleep Quality Index (PSQI) (Buysse et al., 1989). In addition, another questionnaire was used to gather the demographic, socioeconomic, 
184 and health-related characteristics. Questionnaires were distributed to the students and written

185 informed consent of their families was obtained. The students filled out the questionnaires in the 186 classroom under the supervision of the researchers.

187 The socioeconomic and health status levels of the students were determined according to 188 their individual perceptions. In order to determine the perceived economic level, the students 189 were asked the question of "How do you perceive your family’s economic situation?". In order to 190 determine the perceived health status, the students were asked the question of "How is your 191 health in general?". The perceived economic and health situation were evaluated with a five192 (Bishop \& Herron, 2015). Since the number of students who stated the perception of economic situation as "very good" and "very bad" was very few, this variable was grouped as "very badbad" and "very good -good" in the analysis.

The mean age of the students participating in the study was $15.7 \pm 1.20$. In the literature, studies conducted with adolescents indicate that the frequency of poor SQ increases with age (Demirci et al., 2015; Wang et al., 2019). Therefore, in our study, adolescents were divided into two approximately equal groups $(\leq 15$ and $\geq 16)$ to examine the effect of age.

Using the height and weight values declared by each student, the body mass index (BMI) $\left(\mathrm{kg} / \mathrm{m}^{2}\right)$ of the students was calculated. BMI values were classified according to their percentile values (underweight: $<5$ th percentile, healthy weight: 5 th to $<85$ th percentile, overweight: 85 th to $<95$ th percentile, obese: $\geq 95$ th percentile) (World Health Organization, 2021).

\section{Internet addiction (IA)}

Internet addiction was measured using the s-IAT (Pawlikowski, Altstötter-Gleich \& Brand, 2013). Cronbach's alpha coefficient for the original version of the s-IAT is 0.85 (Pawlikowski, Altstötter-Gleich \& Brand, 2013). It is a five-point Likert scale ( $1=$ never, $5=$ very often) (Bishop \& Herron, 2015) consisting of 12 itemsThe total score is between 12 and 60. If the score obtained in the questionnaire is below 31, it is classified as having normal internet use, if it is between 31-37, it shows problematic internet use, and above 37, it is defined as pathological internet use (Pawlikowski, Altstötter-Gleich \& Brand, 2013). The Turkish version of the s-IAT is a reliable and valid scale for adolescents, and its Cronbach's alpha coefficient is 0.86 (Kutlu et al., 2016). In our study, the Cronbach's alpha coefficient was 0.78 . 
214

215

216

217

218

219

220

221

222

223

224

225

226

227

228

229

230

231

232

233

234

235

236

237

238

239

240

241

242

243

244

\section{Smartphone addiction (SA)}

The SAS was used to evaluate SA (Kwon et al., 2013). Cronbach's alpha coefficient for the original version of the SAS is 0.96 (Kwon et al., 2013). It contains six subscales of SA: daily-life disturbance, positive anticipation, withdrawal, cyberspace-oriented relationship, overuse, and tolerance. "Daily-life disturbance", includes inability to work planned, difficulty in concentrating, drowsiness or blurred vision, pain on the wrists or neck, and sleeping disturbance. "Positive anticipation" is defined as getting excited and relieved of stress with smartphone use and feeling empty without a smartphone. "Withdrawal" includes being impatient, moody, and unbearable without a smartphone, constantly thinking about using a smartphone, never giving up on using the smartphone, and getting angry when disturbed while using the smartphone. "Cyberspace-oriented relationship" is defined as the feeling that one's relationships with friends acquired through smartphones are more intimate than relationships with real-life friends, and an uncontrolled sense of loss when one cannot use their smartphone. "Overuse" is defined as a person using their smartphone uncontrollably, preferring to solve a problem using the smartphone instead of asking for help from others, and wanting to use their smartphone again immediately after using it. "Tolerance" is defined as a person trying to limit the use of smartphone but failing to do so (Kwon et al., 2013). SAS is a six-point Likert scale (1= strongly disagree, $6=$ strongly agree) (Bishop \& Herron, 2015) consisting of 33 items. The total score is between 33 and 198, a cut-off point was not suggested. The higher scores on the scale indicate that the addiction is more severe (Kwon et al., 2013). The Turkish version of the SAS is a reliable and valid and its Cronbach's alpha coefficient is reported to be 0.95 (Demirci et al., 2014). In our study, the Cronbach's alpha coefficient was 0.86 .

\section{Sleep quality (SQ)}

Sleep quality was measured using the PSQI (Buysse et al., 1989). Cronbach's alpha coefficient for the original version of the PSQI is 0.83 (Buysse et al., 1989). It consists of seven components: subjective SQ (sleep quality as perceived by the subject), sleep latency (time from going to bed to falling asleep), sleep duration (time spent asleep), habitual sleep efficiency (effective sleeping time of total time spent in bed), sleep disturbances (coughing or snoring loudly, feeling too cold and/or hot, having bad dreams, not breathing comfortably, and waking up in the middle of the night or early morning), use of sleep medication (taking medication to help sleep), and daytime dysfunction (difficulty in staying awake, difficulty in doing tasks during 
245 the day) (Buysse et al., 1989). The answer to each question is different in PSQI. A four-point

246 Likert scale was used in only two questions (Bishop \& Herron, 2015). The total score is between

2470 and 21. Higher scores indicate poor SQ. The suggested cut-off value was used to distinguish

248 between good sleepers (score <5) and poor sleepers (score $\geq 5$ ) (Ăgargün, Kara \& Anlar, 1996;

249 Buysse et al., 1989). The Turkish version of the PSQI is reliable and valid. Its Cronbach's alpha 250 coefficient is 0.79 (A ğargün, Kara \& Anlar, 1996). In our study, the Cronbach's alpha coefficient 251 was 0.64 .

252 Statistical analysis

253 Sociodemographic and individual characteristics of the adolescents were presented as numbers 254 and percentages. Continuous variables were presented as mean \pm standard deviation. We 255 analyzed the normality of the data with the Kolmogorov-Smirnov test. As our data were not 256 normally distributed $(P<0.05)$, we used non-parametric tests. Categorical variables were 257 summarized using percentages and compared using the chi-square test and chi-square test for 258 trend. The Mann-Whitney U test was used to compare the SAS subscale scores in the SQ groups. 259 The relationship between SAS total score, SAS subscale scores, sIAT total score, and PSQI 260 components was determined by the Spearman's correlation analysis. The effect of students' 261 sociodemographic and individual characteristics, IA, and SA on poor SQ was analyzed using the 262 adjusted binary logistic regression (enter method). Statistical analysis was conducted using the 263 IBM Statistical Package of the Social Science for Windows 24.0 (IBM Corp., Armonk, NY, 264 USA) statistics package software. The posthoc power analysis of the study was performed using $265 \mathrm{G}^{*}$ Power software and found to be $0.99(\mathrm{n}=910, \alpha=0.05$, effect size $=0.50)$.

\section{Ethics}

267 The study was conducted in accordance with the principles of the Helsinki Declaration. All 268 students were informed about the aims of the study, and parents signed a written informed 269 consent indicating that their children voluntarily participated in the study. The questionnaires 270 were filled in classrooms. Ethical approval was obtained from the Non-invasive Research Ethics 271 Committee of Dokuz Eylul University, Izmir, Turkey (Decision No: 2018/01-39).

\section{Results}


274 Nine hundred and ten Turkish adolescents were included in this study. The SQ of 58.7\% of the 275 students was poor while $41.3 \%$ had a good SQ. The relationship between some 276 sociodemographic and individual characteristics of the students with their SQ is presented in 277 Table 1. As shown in Table 1, gender, age, paternal education level, perceived health status and 278 perceived economic status of family are significantly associated with sleep quality $(\mathrm{p}<0.01$; $279 \mathrm{p}=0.02 ; \mathrm{p}=0.02 ; \mathrm{p}<0.01 ; \mathrm{p}<0.01$, respectively). The SQ of female students, students in the $\geq 16$ 280 age group, and those whose father's education level $\leq$ high school were significantly poor. The 281 worse the perceived health status of the students was, the poorer the SQ of the students became. 282 Additionally, as the perceived economic status of family deteriorated, the SQ of the students 283 deteriorated significantly.

284 The IA scores of $72.4 \%$ of the students were "normal," $19.2 \%$ were "problematic" and 285 8.4\% were "pathological." As the IA level of the students increased, the SQ also worsened 286 significantly (Table 2).

287 The SAS total score of the students was found to be $77.9 \pm 27.7$ (Min: 33.0, Max: 193.0).

288 The relationship between SA and SQ is presented in Table 3. Students with poor SQ had 289 significantly higher SAS total and sub-components scores.

The correlation between SAS and PSQI scores is shown in Table 4. There was a weak 291 positive correlation between the scores of some subcomponents of SAS, SAS total score, the 292 total score of sIAT, and PSQI subcomponent scores (except for the habitual sleep efficiency). There was a weak positive correlation between the daily-life disturbance and overuse subcomponent scores of the SAS and the PSQI subcomponent scores (except habitual sleep efficiency) (daily-life disturbance; $\mathrm{r}=0.241 ; \mathrm{p}<0.01, \mathrm{r}=0.120 ; \mathrm{p}<0.01, \mathrm{r}=0.158 ; \mathrm{p}<0.01, \mathrm{r}=0.274$; $\mathrm{p}<0.01, \mathrm{r}=0.123 ; \mathrm{p}<0.01, \mathrm{r}=0.382 ; \mathrm{p}<0.01$, overuse; $\mathrm{r}=0.146 ; \mathrm{p}<0.01, \mathrm{r}=0.071 ; \mathrm{p}=0.03, \mathrm{r}=0.117$; $\mathrm{p}<0.01, \mathrm{r}=0.182 ; \mathrm{p}<0.01, \mathrm{r}=0.073 ; \mathrm{p}=0.02, \mathrm{r}=0.257 ; \mathrm{p}<0.01$, respectively). There was a weak positive correlation between the positive anticipation subcomponent score of the SAS and the PSQI subcomponents sleep disturbances $(r=0.122 ; \mathrm{p}<0.01)$, use of sleep medication $(\mathrm{r}=0.093$; $\mathrm{p}<0.01)$ and daytime dysfunction scores $(\mathrm{r}=0.140 ; \mathrm{p}<0.01)$. There was a weak positive correlation between SAS withdrawal and cyberspace-oriented relationship subcomponent scores and PSQI subcomponent scores (excluding sleep latency and habitual sleep efficiency) (withdrawal; $\mathrm{r}=0.099 ; \mathrm{p}<0.01, \mathrm{r}=0.090 ; \mathrm{p}<0.01, \mathrm{r}=0.215 ; \mathrm{p}<0.01, \mathrm{r}=0.093 ; \mathrm{p}<0.01, \mathrm{r}=0.215$; 304 $\mathrm{p}<0.01$, cyberspace-oriented relationship; $\mathrm{r}=0.113 ; \mathrm{p}<0.01, \mathrm{r}=0.080 ; \mathrm{p}=0.01, \mathrm{r}=0.170 ; \mathrm{p}<0.01$, 
$305 \mathrm{r}=0.128 ; \mathrm{p}<0.01, \mathrm{r}=0.189 ; \mathrm{p}<0.01$, respectively). There was a weak positive correlation between

306 the tolerance subcomponent score of the SAS and the subjective $\mathrm{SQ}(\mathrm{r}=0.108 ; \mathrm{p}<0.01)$, sleep 307 duration $(\mathrm{r}=0.097 ; \mathrm{p}<0.01)$, sleep disturbances $(\mathrm{r}=0.166 ; \mathrm{p}<0.01)$, and daytime dysfunction 308 scores $(r=0.237 ; \mathrm{p}<0.01)$ of the PSQI subcomponents (Table 4).

309 A logistic regression analysis of variables affecting poor SQ is shown in Table 5. Poor SQ 310 was 1.39 (95\% CI: $1.05-1.84 ; \mathrm{p}=0.02)$ times higher in the $\geq 16$ age group than in the $\leq 15$ age 311 group. Poor SQ was 1.50 (95\% CI: 1.13-2.00; p<0.01) times higher in female students than male 312 students. Compared to those who perceived their health status as "very good-good," poor sleep 313 quality was 1.74 (95\% CI: 1.12-2.69; $\mathrm{p}=0.01)$ times higher in those who perceived their health 314 status as "moderate," and 6.39 (95\% CI: 1.83-22.30; p<0.01) times higher in those who 315 perceived their health status as "very bad-bad." The poor SQ was 1.45 (95\% CI: 1.05-2.00; $316 \mathrm{p}=0.02$ ) times higher in those who perceived their family's economic status as "moderate" 317 compared to those who perceived their economic status as "very good-good." In addition, poor 318 SQ was 1.83 (95\% CI: 1.22-2.74; $\mathrm{p}<0.01)$ times higher in those with problematic internet use 319 than those with normal internet use scores, and 1.99 (95\% CI: 1.23-3.87; $\mathrm{p}=0.04)$ times higher in 320 those with pathological internet use. A one-point increase in the SAS total score increased poor 321 SQ 1.01 (95\% CI: 1.01-1.02; p<0.01) times. The education level of the students' parents did not 322 affect poor SQ (Table 5).

323

\section{Discussion}

325 Sleep is an indispensable need for Turkish adolescents to achieve physical growth and improve 326 academic performance (Brown et al., 2018). Adolescents must sleep sufficiently to achieve their developmental functions (Tarokh et al., 2016). In this study, we investigated the factors affecting poor SQ in adolescents and the relationship between IA and SA with the poor SQ. We found that IA, SA, the students' age group, gender, perception of health status, and perception of their family's economic status affect poor SQ.

Sleep is important for the cardiovascular and hormonal systems of adolescents whose growth and development are not yet completed (Brown et al., 2018). Therefore, changes in SQ may affect morbidity and academic success (Brown et al., 2018). SQ of approximately two-thirds $(58.7 \%)$ of the students participating in our study was poor. In studies conducted with Turkish adolescents using PSQI, the frequency of poor SQ was similar to the result of our study (54.7\%, 
336 58.6\%) (Akçay \& Akçay, 2018; Koças \& Şaşmaz, 2018). In another study conducted with 337 medical students, the frequency of poor SQ was 62.5\% (Demirci et al., 2015). In studies 338 conducted with adolescents in different countries, the frequency of poor SQ varies between $9.8 \%$ 339 and 60.4\% (de Lima \& Silva, 2018; Huang et al., 2020; Kurugodiyavar et al., 2018; Lin et al., 340 2019; Salama, 2020). In the literature, it is stated that demographic characteristics such as age, 341 gender, and sociocultural factors are also effective in adolescents' sleep (Huang et al., 2020; 342 Koças \& Şaşmaz, 2018; Wang et al., 2019; Özcan, 2020). In this study, we found that 343 adolescents aged 16 and over had 1.4 times poorer SQ than those under 16 years of age. With 344 this result, the third hypothesis of our research was confirmed. Studies conducted with 345 adolescents indicate that the frequency of poor SQ increases with age (Demirci et al., 2015; Wang et al., 2019). There are also studies showing that there is no relationship between the age of adolescents and poor SQ (Huang et al., 2020; Kurugodiyavar et al., 2018; Lin et al., 2019). In the adolescent age group, sleep is a physiological need that may affect thought and attentionseeking activities (Brown et al., 2018; de Lima \& Silva, 2018). Therefore, determining the factors affecting poor SQ and raising awareness in adolescence are important to create positive behavioral changes.

As an interesting finding in our study, poor SQ was 1.5 times higher in female students compared to male students participating in our study. With this result, the third hypothesis of our research was confirmed. Gender differences may affect the sleep patterns of adolescents. But, there is no consensus in the literature regarding the relationship between poor SQ and gender in adolescents. In several studies, poor SQ is reported to be more common in male adolescents (Demirci et al., 2015; Huang et al., 2020; Kurugodiyavar et al., 2018). In others, adolescent girls are more prone to SQ problems than adolescent boys (Demirci, Akgönül, \& Akpinar, 2015; Koças \& Şaşmaz, 2018; Wang et al., 2019). Similar to the result of our study, poor SQ was found 1.7 times higher in female students in a study conducted on adolescents in Brazil (de Lima \& Silva, 2018). In addition to hormonal changes observed in adolescent girls, changes in healthrelated behaviors and electronic device use also negatively affect SQ (Bruni et al., 2015; Lee, Kim \& Choi, 2017; Lin et al., 2019; Wang et al., 2019). Additionally, irregular menstrual cycles due to hormonal changes and waking up habits at night due to menstrual pain may adversely affect the SQ of female adolescents (Kazama, Maruyama \& Nakamura, 2015; Nam, Han \& Lee, 2017). Although it is not in the scope of this study, health-related behaviors, self-actualization, 
367 interpersonal support, and stress management behavior observed in adolescent girls may also 368 affect SQ.

369 Poor SQ may cause mood, behavior, memory, and attention problems in adolescents. The 370 physiological and psychological effects of diseases may impair the duration and quality of sleep.

371 Diseases that cause physical discomfort or problems such as anxiety and depression may be related to sleep problems. In studies conducted with adolescents, those who had smoking habits (Lin et al., 2019), who were diagnosed with depression (Huang et al., 2020; Onat et al., 2019), who had physical and mental health problems (Huang et al., 2020), and who cannot cope with stress (Wang et al., 2019) were found to have poorer SQ. In our study, we identified that students who were not satisfied with their health had poor SQ. With this result, the third hypothesis of our research was confirmed. Identifying and treating the underlying causes of problems affecting general health in adolescence may help improve SQ.

Another finding of our study, we found a relationship between the perception of the family's economic status and the SQ of Turkish adolescents. Poor SQ was common in those who perceived their economic situation as bad. With this result, the third hypothesis of our research was confirmed. However, our results could not confirm one of the third hypotheses of our study, that 'parental education level negatively affect SQ'. It is reported that low socioeconomic level is significantly associated with short sleep (Knutson, 2013). However, there are also studies in the literature that do not find a relationship between adolescents' perception of the family's economic situation and their family's education level and poor sleep quality (Huang et al., 2020; Onat et al., 2019; Demirci et al., 2015). The socioeconomic and cultural structure of the family may affect the physical and mental health of adolescents. This situation may cause a deterioration in SQ among adolescents.

In recent years, computer and internet usage has become an indispensable part of life. Today, adolescents spend a lot of time on the internet (Bilgrami et al., 2017). The internet is considered a technological miracle that supports young people's access to information, research, problem-solving, creativity, and critical thinking (Bilgrami et al., 2017). However, excessive internet use brings many health problems. There are many studies examining the relationship between IA and SQ in the literature: In a study conducted on college students in Taiwan, the SQ of students with IA was 1.05 times worse than students without IA (Lin et al., 2019). A study 
398

399

400

401

402

403

404

405

406

407

408

409

410

411

412

413

414

415

416

417

418

419

420

421

422

423

424

425

426

427

428

scores (Demirci et al., 2015). In studies conducted in different areas of the world, IA has been shown to cause poor SQ and sleep problems in adolescents (Akçay \& Akçay, 2018; Bruni et al., 2015; Ekinci et al., 2014; Koças \& Şaşmaz, 2018; Onat et al., 2019; Salama, 2020). Similarly, in our study, poor SQ was 1.8 times higher in students with problematic internet use and 2.0 times higher in students with pathological internet use compared to students who were not internet addicts. With this result, the first hypothesis of our research was confirmed. In a study, conducted on a sample similar to our study, results were similar to our findings (Koças \& Şaşmaz, 2018). Accordingly, IA is an important risk factor for poor SQ. Light and sound coming from devices such as computers, tablets, and smartphones may cause poor SQ by disrupting the individual's sleep rhythm, delaying the transition to sleep, shortening the time remaining for sleep, and causing breaks during sleep (Koças \& Şaşmaz, 2018). IA and insufficient sleep may cause unwanted consequences in daily life and school life (Salama, 2020; Wang et al., 2019). In addition, there may be multiple and complex interactions between IA and mental problems such as anxiety, depression, and stress (Choi et al., 2015; Lachmann et al., 2017; Salama, 2020). The prevalence of IA was high in the adolescents participating in our study. It may be important to investigate this issue, as IA may cause mental problems as well as the deterioration of SQ.

An important finding in our study was the relationship between SA and poor SQ. Adolescents mostly use smartphones for social networking, messaging, and internet access (Demirci, Akgönül \& Akpinar, 2015; Lee, Kim \& Choi, 2017). Therefore, in the literature, SA is more common in adolescents with IA (Choi et al., 2015). In our study, students with poor SQ had higher SAS total and subcomponent scores (daily-life disturbance, positive anticipation, withdrawal, cyberspace-oriented relationship, overuse, and tolerance). We found a positive correlation between the SAS total score and the PSQI subcomponents (subjective SQ, sleep latency, sleep duration, sleep disturbances, use of sleep medication, and daytime dysfunction). With this result, the second hypothesis of our research was confirmed. SA and the habit of using smartphones negatively affect SQ and cause poor SQ in adolescents (Demirci, Akgönül \& Akpinar, 2015; Huang et al., 2020; Kang et al., 2020; Kurugodiyavar et al., 2018; Wang et al., 2019; Xie, Dong \& Wang, 2018). In a one-year follow-up study of Chinese adolescents, no relationship was found between SA and anxiety and depression (Kang et al., 2020). However, in another study conducted in China, a significant relationship was shown between problematic smartphone use and eye problems, immune system disorders, and fatigue symptoms (Xie, Dong 
$429 \&$ Wang, 2018). In other studies, SA in adolescents is shown to be an important risk factor for 430 mental illnesses such as stress, anxiety, and depression (Demirci, Akgönül \& Akpinar, 2015; 431 Panova \& Carbonell, 2018). The prevalence of SA was high in the adolescents participating in 432 our study. Since SA may cause various health problems as well as the deterioration of SQ, studies investigating the relationship of SA with various diseases may provide significant

434

435

436

437

438

439

440

441

442

443

444

445

446

447

448

449

450

451

452

453

454

455

456

457

458

459

benefits. Considering that $\mathrm{SA}$ is a public health problem, a program that will raise awareness in students and their families with a multidisciplinary approach should be created. Proper use of technology, technology addiction, time management, and the importance of healthy living habits may be added to the curriculum. In order to reduce the time they spend on smartphones and internet, opportunities to engage in activities related to culture, sport, and art should be promoted. Initiatives to be implemented to prevent SA and IA in adolescents may also improve SQ. Additionally, counseling which aims at the behavioral change to increase the SQ of students is strongly recommended.

We agree with the literature that excessive use of the Internet and mobile phones negatively affects sleep (Bruni et al., 2015; Huang et al., 2020; Kang et al., 2020; de Lima \& Silva, 2018; Lin et al., 2019; Wang et al, 2021; Xie, Dong \& Wang, 2018). However, it is an interesting result that there is no relationship between IA and SA and habitual sleep efficiency, which is one of the subcomponents of SQ. In the literature, there are studies showing that the habitual sleep time is longer in women than in men (Knutson, 2013), there is no difference between the obese and control groups in terms of habitual sleep efficiency (Eliacik et al., 2016), and habitual sleep efficiency is higher in depressed adolescents (Onat et al., 2019). No explanatory information was found in the literature on this subject. In order to determine the reasons for this relationship, it would be appropriate to conduct follow-up studies in which sleep quality in adolescents is determined by measurement.

This study had some limitations. First, all data were obtained from self-reported questionnaires. The recall factor may have played a role. However, this limitation cannot be interpreted as a random error and cannot be considered as bias. Because the same factor is effective for those with good sleep quality. Second, due to the limitations of the cross-sectional study, we could only determine the relationship between individual variables, but not the exact cause-effect relationships. Therefore, a follow-up study may be conducted to reveal the exact relationship.

Peer] reviewing PDF | (2021:08:64535:3:0:NEW 11 Jan 2022) 
460 Conclusions

461 In our study, IA and SA were associated with the poor SQ in Turkish adolescents. Age ( $\geq 16$ 462 years), gender (female), bad health status, and moderate economic status of the family were other 463 factors that were associated with the poor SQ. Identifying students in the adolescent age group 464 with poor SQ should be the main step in addressing the issue. Conducting interventional studies 465 examining the effect of cultural environment and behavioral treatments on SQ, IA and SA may 466 be important in understanding and solving the problem.

467

468

\section{Acknowledgements}

469

470

471

472

473

474

475

476

477

478

479

480

481

482

483

484

485

486

The authors would like to thank students and their families. The authors did not receive support from any organization for the submitted work.

\section{References}

Ağargün MY, Kara H, Anlar Ö. 1996. The validity and reliability of the Pittsburgh Sleep Quality Index (in Turkish). Turkish Journal of Psychiatry, 7, 107-15.

Akçay D, Akçay, BD. 2018. The influence of media on the sleep quality in adolescents. The Turkish Journal of Pediatrics, 60(3), 255-263. https://doi.org/10.24953/turkjped.2018.03.004

Bilgrami Z, McLaughlin L, Milanaik R, Adesman A. 2017. Health implications of new-age technologies: a systematic review. Minerva Pediatrica, 69(4), 348-367. https://doi.org/10.23736/S0026-4946.17.04937-4

Bishop PA, Herron RL. 2015. Use and Misuse of the Likert Item Responses and Other Ordinal Measures. International Journal of Exercise Science, 8(3), 297-302. Available at 
487 https://www.ncbi.nlm.nih.gov/pmc/articles/PMC4833473/pdf/ijes_08_03_297.pdf (accessed 19 488 December 2021).

489

490 Brown WJ, Wilkerson AK, Boyd, SJ, Dewey D, Mesa F, Bunnell BE. 2018. A review of sleep 491 disturbance in children and adolescents with anxiety. Journal of Sleep Research, 27(3), e12635. 492 https://doi.org/10.1111/jsr.12635

493

494 Bruni O, Sette S, Fontanesi L, Baiocco R, Laghi F, Baumgartner E. 2015. Technology use and 495 sleep quality in preadolescence and adolescence. Journal of Clinical Sleep Medicine, 11(12), 496 1433-1441. https://doi.org/10.5664/jcsm.5282

497

498

Buysse DJ, Reynolds III CF, Monk TH, Berman, SR, Kupfer DJ. 1989. The Pittsburgh Sleep 499 Quality Index: a new instrument for psychiatric practice and research. Psychiatry 500 Research, 28(2), 193-213. https://doi.org/10.1016/0165-1781(89)90047-4

501

502

Choi SW, Kim DJ, Choi JS, Ahn H, Choi EJ, Song WY, Kim S, Youn H. 2015. Comparison of 503 risk and protective factors associated with smartphone addiction and Internet addiction. Journal 504 of Behavioral Addictions, 4(4), 308-314. https://doi.org/10.1556/2006.4.2015.043

505

506

507

508

Demirci A, Doğan R, Matrak YC, Kuruoğlu E, Mevsim V. 2015. The effect of problematic internet use on the sleep quality of medical students (in Turkish). Turkish Journal of Family Medicine and Primary Care, 9(4), 143-149. https://doi.org/10.5455/tjfmpc.181131

509

510

Demirci K, Akgönül M, Akpinar A. 2015. Relationship of smartphone use severity with sleep 511 quality, depression, and anxiety in university students. Journal of Behavioral Addictions, 4(2), 512 85-92. https://doi.org/10.1556/2006.4.2015.010

513

514 Demirci K, Orhan H, Demirdas A, Akpinar A, Sert H. 2014. Validity and reliability of the 515 Turkish version of the smartphone addiction scale in a younger population. Bulletin of Clinical 516 Psychopharmacology, 24(3), 226-234. https://doi.org/10.5455/bcp.20140710040824 
518 Ekinci Ö, Çelik T, Savaş N, Toros F. 2014. Association between internet use and sleep problems

519 in adolescents. Noro Psikiyatri Arsivi, 51(2), 122-128. https://doi.org/10.4274/npa.y6751

520

521 Eliacik K, Bolat N, Koçyiğit C, Kanik A, Selkie E, Yilmaz H, Catli G, Dundar NO, Dundar BN.

522 2016. Internet addiction, sleep and health-related life quality among obese individuals: a 523 comparison study of the growing problems in adolescent health. Eating and Weight 524 Disorders, 21(4), 709-717. https://doi.org/10.1007/s40519-016-0327-z

525

526 Huang Q, Li Y, Huang S, Qi J, Shao T, Chen X, Liao Z, Lin S, Zhang X, Cai Y, Chen H. 2020.

527 Smartphone use and sleep quality in Chinese college students: a preliminary study. Frontiers in

528 Psychiatry, 11, 352. https://doi.org/10.3389/fpsyt.2020.00352

529

530 International Telecommunication Union Development Sector. 2021. Measuring digital 531 development facts and figures 2020. ITU Publication. Available at https://www.itu.int/en/ITU532 D/Statistics/Documents/facts/FactsFigures2020.pdf(accessed 08 August 2021).

533

534 Kang Y, Liu S, Yang L, Xu B, Lin L, Xie L, Zhang W, Zhang J, Zhang B. 2020. Testing the 535 bidirectional associations of mobile phone addiction behaviors with mental distress, sleep 536 disturbances, and sleep patterns: a one-year prospective study among Chinese college 537 students. Frontiers in Psychiatry, 11, 634. https://doi.org/10.3389/fpsyt.2020.00634

538

539 Kazama M, Maruyama K, Nakamura K. 2015. Prevalence of dysmenorrhea and its correlating 540 lifestyle factors in Japanese female junior high school students. The Tohoku Journal of 541 Experimental Medicine, 236(2), 107-113. https://doi.org/10.1620/tjem.236.107

542

543 Knutson KL. 2013. Sociodemographic and cultural determinants of sleep deficiency: 544 implications for cardiometabolic disease risk. Social Science \& Medicine, 79, 7-15. 545 https://doi.org/10.1016/j.socscimed.2012.05.002

546 
547 Kocamaz D, Badat T, Maden T, Tuncer A. 2020. The relationship between the smartphone 548 addiction, sleep quality, and depression among university students (in Turkish). Journal of 549 Exercise Therapy and Rehabilitation. 7(3), 253-259.

550

551 Koças F, Şaşmaz T. 2018. Internet addiction increases poor sleep quality among high school 552 students. Turkish Journal of Public Health, 16(3), 167-177. https://doi.org/10.20518/tjph.407717 553

Kurugodiyavar MD, Sushma HR, Godbole M, Nekar MS. 2018. Impact of smartphone use on 555 quality of sleep among medical students. International Journal of Community Medicine and 556 Public Health, 5(1), 101-109. https://dx.doi.org/10.18203/2394-6040.ijcmph20175604

557

558 Kutlu M, Savc1 M, Demir Y, Aysan F. 2016. Turkish adaptation of Young's Internet Addiction 559 Test-short form: a reliability and validity study on university students and adolescents (in 560 Turkish). Anatolian Journal of Psychiatry, 17(Suppl.), 69-76. 561 https://doi.org/10.5455/apd.190501

562

563 Kwon M, Lee JY, Won WY, Park JW, Min JA, Hahn C, Gu X, Choi JH, Kim DJ. 2013. 564 Development and validation of a smartphone addiction scale (SAS). PloS One, 8(2), e56936. 565 https://doi.org/10.1371/journal.pone.0056936

566

567 Lachmann B, Sariyska R, Kannen C, Stavrou M, Montag C. 2017. Commuting, life-satisfaction 568 and internet addiction. International Journal of Environmental Research and Public 569 Health, 14(10), 1176. https://doi.org/10.3390/ijerph14101176

570

571 Lee H, Kim JW, Choi TY. 2017. Risk factors for smartphone addiction in Korean adolescents: 572 smartphone use patterns. Journal of Korean Medical Science,32(10), 1674-1679. 573 https://doi.org/10.3346/jkms.2017.32.10.1674

574

575 Lemma S, Berhane Y, Worku A, Gelaye B, Williams MA. 2014. Good Quality Sleep is 576 Associated with Better Academic Performance among University Students in Ethiopia. Sleep 577 Breath, 18(2), 257-263. https://doi:10.1007/s11325-013-0874-8. 
579 de Lima TR, Silva D. 2018. Association of sleep quality with sociodemographic factors and 580 lifestyle in adolescents from southern Brazil. World Journal of Pediatrics, 14(4), 383-391. 581 https://doi.org/10.1007/s12519-018-0136-8

582

583 Lin PH, Lee YC, Chen KL, Hsieh PL, Yang SY, Lin YL. 2019. The relationship between sleep 584 quality and internet addiction among female college students. Frontiers in Neuroscience, 13, 585 599. https://doi.org/10.3389/fnins.2019.00599

586

587 Medic G, Wille M, Hemels ME. 2017. Short- and long-term health consequences of sleep 588 disruption. Nature and Science of Sleep, 9, 151-161. https://doi.org/10.2147/NSS.S134864 589

590 Nam GE, Han K, Lee G. 2017. Association between sleep duration and menstrual cycle 591 irregularity in Korean female adolescents. Sleep Medicine, 35, 62-66. 592 https://doi.org/10.1016/j.sleep.2017.04.009

593

594 Onat M, Özyurt G, Öztürk Y, Pekcanlar Akay A. 2019. The relationship between problematic 595 internet use, sleep quality and impulsivity in adolescents with major depressive disorder. 596 Anatolian Journal of Psychiatry, 20(5), 491-498. https://doi.org/10.5455/apd.17978

597

598 Özcan A. 2020. The relationship between internet addiction, loneliness and sleep quality in 599 nursing students (in Turkish). Journal of Samsun Health Sciences, 5(1), 67-72.

600

601 Panova T, Carbonell X. 2018. Is smartphone addiction really an addiction? Journal of 602 Behavioral Addictions, 7(2), 252-259. https://doi.org/10.1556/2006.7.2018.49

603

604 Pawlikowski M, Altstötter-Gleich C, Brand M. 2013. Validation and psychometric properties of 605 a short version of Young's Internet Addiction Test. Computers in Human Behaviour, 29(3), 606 1212-1223. https://doi.org/10.1016/j.chb.2012.10.014

607 
608 Salama B. 2020. Prevalence and associated factors of Internet addiction among undergraduate 609 students at Al-Beheira Governorate, Egypt. International Journal of Public Health, 65(6), 905610 910. https://doi.org/10.1007/s00038-020-01429-9

611

612 Shaw M, Black DW. 2008. Internet addiction: definition, assessment, epidemiology and clinical 613 management. CNS Drugs, 22(5), 353-365. https://doi.org/10.2165/00023210-200822050-00001

614

615 Statista. 2021. Number of smartphone users worldwide from 2016 to 2026. Available at 616 https://www.statista.com/statistics/330695/number-of-smartphone-users-

617 worldwide/\#statisticContainer (accessed 08 August 2021).

618

619 Tarokh L, Saletin JM, Carskadon MA. 2016. Sleep in adolescence: Physiology, cognition and 620 mental health. Neuroscience and Biobehavioral Reviews, 70, 182-188. 621 https://doi.org/10.1016/j.neubiorev.2016.08.008

622

623 Turkish Statistical Institute. 2021. Survey on Information and Communication Technology (ICT) 624 Usage in Households and by Individuals, 2021. https://data.tuik.gov.tr/Bulten/Index?p=Survey625 on-Information-and-Communication-Technology-(ICT)-Usage-in-Households-and-by-

626 Individuals-2021-37437 (accessed 10 October 2021).

627

628 Wang PY, Chen KL, Yang SY, Lin PH. 2019. Relationship of sleep quality, smartphone 629 dependence, and health-related behaviors in female junior college students. PloS One, 14(4), 630 e0214769. https://doi.org/10.1371/journal.pone.0214769

631

632 Wang W, Du X, Guo Y, Li W, Zhang S, Guo L, Lu C. 2021. Association between problematic 633 internet use and behavioral/emotional problems among Chinese adolescents: the mediating role 634 of sleep disorders. PeerJ, 9, e10839. https://doi.org/10.7717/peerj.10839

635

636 World Health Organization. 2010. Participant manual: IMAI one-day orientation on adolescents 637 living with HIV. Geneva.

638 
639 World Health Organization. 2021. BMI-for-age (5-19 years). Available at

640 https://www.who.int/tools/growth-reference-data-for-5to19-years/indicators/bmi-for-age

641 (accessed 08 August 2021).

642

643 Xie X, Dong Y, Wang J. 2018. Sleep quality as a mediator of problematic smartphone use and 644 clinical health symptoms. Journal of Behavioral Addictions, 7(2), 466-472.

645 https://doi.org/10.1556/2006.7.2018.40

646 


\section{Table $\mathbf{1}$ (on next page)}

Relationship between some sociodemographic and individual characteristics of the students and their sleep quality $(n=910)$ 
1 Table 1. Relationship between some sociodemographic and individual characteristics of the 2 students and their sleep quality $(n=910)$

\begin{tabular}{|c|c|c|c|c|c|}
\hline \multicolumn{2}{|l|}{ Characteristics } & \multicolumn{2}{|c|}{ Sleep quality } & \multirow[b]{2}{*}{$\chi^{2}$-value } & \multirow[b]{2}{*}{$p^{*}$} \\
\hline & & $\begin{array}{l}\text { Poor } \\
(n=534) \\
n(\%)\end{array}$ & $\begin{array}{l}\text { Good } \\
(n=376) \\
n(\%)\end{array}$ & & \\
\hline \multirow{2}{*}{$\begin{array}{l}\text { Age } \\
\text { (years) }\end{array}$} & $\geq 16$ & $301(62.2)$ & $183(37.8)$ & \multirow[t]{2}{*}{5.25} & \multirow[t]{2}{*}{0.022} \\
\hline & $\leq 15$ & $233(54.7)$ & $193(45.3)$ & & \\
\hline \multirow[t]{2}{*}{ Gender } & Female & $289(64.4)$ & $160(35.6)$ & \multirow[t]{2}{*}{11.81} & \multirow[t]{2}{*}{0.001} \\
\hline & Male & $245(53.1)$ & $216(46.9)$ & & \\
\hline \multirow{2}{*}{$\begin{array}{l}\text { Paternal } \\
\text { education level }\end{array}$} & $\leq$ High school & $255(62.8)$ & $151(37.2)$ & \multirow[t]{2}{*}{5.15} & \multirow[t]{2}{*}{0.023} \\
\hline & University & $279(55.4)$ & $225(44.6)$ & & \\
\hline \multirow{2}{*}{$\begin{array}{l}\text { Maternal } \\
\text { education level }\end{array}$} & $\leq$ High school & $213(60.3)$ & $140(39.7)$ & \multirow[t]{2}{*}{0.65} & \multirow[t]{2}{*}{0.419} \\
\hline & University & $321(57.6)$ & $236(42.4)$ & & \\
\hline \multirow{3}{*}{$\begin{array}{l}\text { Perceived } \\
\text { health status }\end{array}$} & Very good-good & $426(55.9)$ & $336(44.1)$ & \multirow[t]{3}{*}{18.01} & \multirow[t]{3}{*}{$<0.001 \#$} \\
\hline & Moderate & $85(69.7)$ & $37(30.3)$ & & \\
\hline & Bad-very bad & $23(88.5)$ & $3(11.5)$ & & \\
\hline \multirow{3}{*}{$\begin{array}{l}\text { Perceived } \\
\text { economic } \\
\text { status of } \\
\text { family }\end{array}$} & Very good-good & $328(55.0)$ & $268(45.0)$ & \multirow[t]{3}{*}{9.49} & \multirow[t]{3}{*}{ 0.003\# } \\
\hline & Moderate & $194(65.5)$ & $102(34.5)$ & & \\
\hline & Bad-very bad & $12(66.7)$ & $6(33.3)$ & & \\
\hline \multirow{4}{*}{$\begin{array}{l}\text { Body Mass } \\
\text { Index }\end{array}$} & Underweight & $12(70.6)$ & $5(29.4)$ & \multirow[t]{4}{*}{2.86} & \multirow[t]{4}{*}{0.414} \\
\hline & Normal & $412(59.5)$ & $280(40.5)$ & & \\
\hline & Overweight & $87(53.7)$ & $75(46.3)$ & & \\
\hline & Obese & $23(59.0)$ & $16(41.0)$ & & \\
\hline
\end{tabular}

3 Notes:

4 * Pearson's Chi-square test

5 \# Chi-square test for trend. 


\section{Table 2 (on next page)}

Relationship between internet addiction and sleep quality 
1 Table 2. Relationship between internet addiction and sleep quality

\begin{tabular}{|c|c|c|c|c|c|c|}
\hline \multirow[b]{2}{*}{ Internet addiction } & \multicolumn{4}{|c|}{ Sleep quality } & \multirow[b]{2}{*}{$\chi^{2}$-value } & \multirow[b]{2}{*}{$p^{*}$} \\
\hline & \multicolumn{2}{|c|}{$\begin{array}{l}\text { Poor } \\
\text { n }\end{array}$} & $\begin{array}{l}\text { Goo } \\
\text { n }\end{array}$ & $\%$ & & \\
\hline Normal & 346 & 52.5 & 313 & 47.5 & 38.90 & $<0.001$ \\
\hline Problematic & 127 & 72.6 & 48 & 27.4 & & \\
\hline Pathological & 61 & 80.3 & 15 & 19.7 & & \\
\hline
\end{tabular}

2 Notes:

$3 *$ Chi-square test for trend.

4

5

6

7

8

9

10

11

12

13

14

15

16

17

18

19

20

21

22

23

24

25

26

27

28

29

30

31

32

33

34

35

36 
38

39

40 


\section{Table 3(on next page)}

Relationship between smartphone addiction and sleep quality 
1 Table 3. Relationship between smartphone addiction and sleep quality

2

\begin{tabular}{|c|c|c|c|c|c|c|c|}
\hline \multirow[b]{2}{*}{$\begin{array}{l}\text { Sleep } \\
\text { quality }\end{array}$} & \multicolumn{6}{|c|}{ SAS Subscales } & \multirow{2}{*}{$\begin{array}{l}\text { SAS total } \\
\text { score }\end{array}$} \\
\hline & $\begin{array}{c}\text { Daily-life } \\
\text { disturbance }\end{array}$ & $\begin{array}{c}\text { Positive } \\
\text { anticipation }\end{array}$ & Withdrawal & $\begin{array}{l}\text { Cyberspace- } \\
\text { oriented } \\
\text { relationship }\end{array}$ & Overuse & Tolerance & \\
\hline $\begin{array}{l}\text { Good } \\
(n=376)\end{array}$ & $9.48 \pm 4.32$ & $16.36 \pm 7.08$ & $12.72 \pm 5.82$ & $14.02 \pm 5.26$ & $10.39 \pm 4.46$ & $6.97 \pm 3.99$ & $69.95 \pm 23.74$ \\
\hline $\begin{array}{l}\begin{array}{l}\text { Poor } \\
(n=534)\end{array}\end{array}$ & $12.65 \pm 5.48$ & $18.52 \pm 8.28$ & $15.15 \pm 6.92$ & $16.12 \pm 6.58$ & $12.81 \pm 5.08$ & $8.30 \pm 4.24$ & $83.55 \pm 28.97$ \\
\hline$p^{*}$ & $<0.001$ & $<0.001$ & $<0.001$ & $<0.001$ & $<0.001$ & $<0.001$ & $<0.001$ \\
\hline
\end{tabular}

3 Notes:

4 *Mann-Whitney U test

5

6

7

8

9

10

11

12

13

14

15

16

17

18

19

20

21

22

Peer] reviewing PDF | (2021:08:64535:3:0:NEW 11 Jan 2022) 


\section{Table 4 (on next page)}

Correlation between the smartphone addiction scale and Pittsburgh Sleep Quality Index scores 
1 Table 4. Correlation between the smartphone addiction scale and Pittsburgh Sleep Quality 2 Index scores

\begin{tabular}{|c|c|c|c|c|c|c|c|}
\hline \multirow[b]{2}{*}{ SAS subscales } & \multicolumn{7}{|c|}{ Pittsburgh Sleep Quality Index scores } \\
\hline & $\begin{array}{c}\text { Subjective } \\
\text { sleep } \\
\text { quality }\end{array}$ & $\begin{array}{c}\text { Sleep } \\
\text { latency }\end{array}$ & $\begin{array}{c}\text { Sleep } \\
\text { duration }\end{array}$ & $\begin{array}{l}\text { Habitual } \\
\text { sleep } \\
\text { efficiency }\end{array}$ & $\begin{array}{c}\text { Sleep } \\
\text { disturbances }\end{array}$ & $\begin{array}{l}\text { Use of sleep } \\
\text { medication }\end{array}$ & $\begin{array}{c}\text { Daytime } \\
\text { dysfunction }\end{array}$ \\
\hline Daily-life disturbance & $0.241 * *$ & $0.120 * *$ & $0.158 * *$ & 0.033 & $0.274 * *$ & $0.123 * *$ & $0.382 * *$ \\
\hline Positive anticipation & 0.017 & 0.029 & 0.038 & -0.045 & $0.122 * *$ & $0.093 *$ & $0.140 * *$ \\
\hline Withdrawal & 0.099* & 0.040 & $0.090 *$ & -0.054 & $0.215 * *$ & 0.093* & $0.215 * *$ \\
\hline $\begin{array}{l}\text { Cyberspace-oriented } \\
\text { relationship }\end{array}$ & $0.113 * *$ & 0.051 & $0.080 \%$ & 0.007 & $0.170 * *$ & $0.128 * *$ & $0.189 * *$ \\
\hline Overuse & $0.146 * *$ & 0.071* & $0.117 * *$ & -0.063 & $0.182 * *$ & $0.073 *$ & $0.257 * *$ \\
\hline Tolerance & $0.108 * *$ & 0.025 & $0.097 *$ & 0.002 & $0.166 * *$ & 0.062 & $0.237 * *$ \\
\hline SAS total score & $0.149 * *$ & $0.070 *$ & $0.121 * *$ & -0.030 & $0.238 * *$ & $0.123 * *$ & $0.292 * *$ \\
\hline $\begin{array}{l}\text { Internet addiction } \\
\text { total score }\end{array}$ & $0.202 * *$ & $0.129 * *$ & $0.142 * *$ & 0.030 & $0.217 * *$ & 0.086* & $0.310 * *$ \\
\hline
\end{tabular}

3 Notes:

$4 * p<0.05$

$5 * * p<0.001$

6 The results are expressed as Rho value.

7 Significant $p$ values were shown in bold. 


\section{Table 5 (on next page)}

A logistic regression analysis among variables influencing poor sleep quality 
1 Table 5. A logistic regression analysis among variables influencing poor sleep quality

\begin{tabular}{|c|c|c|c|c|}
\hline & & $\begin{array}{l}\text { Crude } \\
\text { OR } \\
(95 \% \text { CI) }\end{array}$ & $\begin{array}{l}\text { Adjusted } \\
\text { OR ** } \\
(95 \% \text { CI) }\end{array}$ & $p$ \\
\hline \multirow[t]{2}{*}{ Age (year) } & $\leq 15^{*}$ & 1.00 & 1.00 & \\
\hline & $\geq 16$ & $\begin{array}{l}1.36 \\
(1.04-1.77)\end{array}$ & $\begin{array}{l}1.39 \\
(1.05-1.84)\end{array}$ & 0.021 \\
\hline \multirow[t]{2}{*}{ Gender } & Male* & 1.00 & 1.00 & \\
\hline & Female & $\begin{array}{l}1.59 \\
(1.22-2.09)\end{array}$ & $\begin{array}{l}1.50 \\
(1.13-2.00)\end{array}$ & 0.005 \\
\hline \multirow{2}{*}{$\begin{array}{l}\text { Paternal } \\
\text { education level }\end{array}$} & University* & 1.00 & 1.00 & \\
\hline & $\leq$ High school & $\begin{array}{l}1.36 \\
(1.04-1.78 \\
\end{array}$ & $\begin{array}{l}0.82 \\
(0.58-1.16)\end{array}$ & 0.280 \\
\hline \multirow{2}{*}{$\begin{array}{l}\text { Maternal } \\
\text { education level }\end{array}$} & University* & 1.00 & 1.00 & \\
\hline & $\leq$ High school & $\begin{array}{l}1.11 \\
(0.85-1.46)\end{array}$ & $\begin{array}{l}1.29 \\
(0.91-1.81)\end{array}$ & 0.145 \\
\hline \multirow[t]{3}{*}{$\begin{array}{l}\text { Perceived } \\
\text { health status }\end{array}$} & $\begin{array}{l}\text { Very good- } \\
\text { good* }\end{array}$ & 1.00 & 1.00 & \\
\hline & Moderate & $\begin{array}{l}1.81 \\
(1.20-2.75)\end{array}$ & $\begin{array}{l}1.74 \\
(1.12-2.69)\end{array}$ & 0.013 \\
\hline & Bad-very bad & $\begin{array}{l}6.03 \\
(1.97-25.47)\end{array}$ & $\begin{array}{l}6.39 \\
(1.83-22.30)\end{array}$ & 0.004 \\
\hline \multirow{3}{*}{$\begin{array}{l}\text { Perceived } \\
\text { economic } \\
\text { status of the } \\
\text { family }\end{array}$} & $\begin{array}{l}\text { Very good- } \\
\text { good* }\end{array}$ & 1.00 & 1.00 & \\
\hline & Moderate & $\begin{array}{l}1.55 \\
(1.16-2.07)\end{array}$ & $\begin{array}{l}1.45 \\
(1.05-2.00)\end{array}$ & 0.021 \\
\hline & Bad-very bad & $\begin{array}{l}1.63 \\
(0.61-4.77)\end{array}$ & $\begin{array}{l}0.90 \\
(0.29-2.71)\end{array}$ & 0.854 \\
\hline \multirow{3}{*}{$\begin{array}{l}\text { Internet } \\
\text { addiction }\end{array}$} & Normal* & 1.00 & 1.00 & \\
\hline & Problematic & $\begin{array}{l}2.39 \\
(1.66-3.46) \\
\end{array}$ & $\begin{array}{l}1.83 \\
(1.22-2.74) \\
\end{array}$ & 0.003 \\
\hline & Pathological & $\begin{array}{l}3.67 \dagger \\
(2.08-6.79)\end{array}$ & $\begin{array}{l}1.99 \\
(1.23-3.87)\end{array}$ & 0.043 \\
\hline SAS total score & $\begin{array}{l}\text { Every 1-point } \\
\text { increment }\end{array}$ & - & $\begin{array}{l}1.01 \\
(1.00-1.02)\end{array}$ & $<0.001$ \\
\hline \multicolumn{5}{|c|}{$\mathrm{R}^{2}=0.150 ;$ Constant $\mathrm{B}=-1.527 ; \mathrm{S} . \mathrm{E}=0.266 ; \operatorname{Exp}(\mathrm{B})=0.217(p<0.0001)$} \\
\hline
\end{tabular}


7 Significant $p$ values were shown in bold.

8

PeerJ reviewing PDF | (2021:08:64535:3:0:NEW 11 Jan 2022) 